\title{
Bilaterality of tears of the retinal pigment epithelium
}

\author{
ELAINE L CHUANG* AND ALAN C BIRD \\ From the Department of Clinical Ophthalmology, Institute of Ophthalmology, \\ Moorfields Eye Hospital, London
}

SUMmARY Eyes with tears of detached retinal pigment epithelium have been studied for up to 10 years following the acute event. In a retrospective study it has been determined that such a lesion in one eye implies a high risk of a similar event occurring in the fellow eye. Patients with loss of vision in their second eye as a result of a pigment epithelial tear were also studied; in 10 of 22 patients a similar lesion could be identified in the first eye. These observations suggest that these patients have specific changes at the level of Bruch's membrane which predispose to this particular manifestation of age related macular disease.

Since they were first described in $1981^{1}$ rips or tears of the retinal pigment epithelium have been recognised increasingly as a cause of severe central visual loss in age related macular degeneration. ${ }^{2-14}$

With continuing review of patients suffering an acute pigment epithelial tear in one eye we have observed or suspected this complication in fellow eyes frequently. Therefore we have sought to determine whether or not tears occur bilaterally more commonly than would be expected by chance alone.

Such a retrospective study requires that tears remain recognisable for some time after the acute event. In a previous study of 63 eyes it has been shown that these lesions undergo gradual modifica- . tion over months to years. ${ }^{15}$ The bed of the tear becomes replaced by a pale fibrous plaque or by pigment epithelium over a period of a few weeks. This is followed by progressive scarring and retinal pigment epithelial hyperplasia which gradually obscure the ophthalmoscopic features by which the original nature of the lesion can be recognised. More rapid modification of the appearance of the lesion occurs in the presence of choroidal neovascularisation, either preceding or following a rip, and of significant subretinal blood. From this review it was established that a lesion can be identified reliably as a tear of the pigment epithelium in $94 \%$ of cases after one year, $77 \%$ at two years, but in none after six years.

*Current address: Bascom Palmer Eye Institute, Miami, Florida 33101, USA.

Correspondence to Dr A C Bird, Professorial Unit, Moorfields Eye Hospital, City Road, London EC1V 2PD.

\section{Patients and methods}

A review of clinical and photographic records from the Retinal Diagnostic Department of Moorfields Eye Hospital between 1976 and 1986 was carried out to identify patients in whom the diagnosis of a pigment epithelial tear was made in at least one eye. Diagnostic features of acute lesions were: (1) sharply defined pigment epithelial discontinuity; (2) an exposed area of Bruch's membrane and choroid denuded of overlying RPE (the 'bed' of the tear); (3) an elevated mound of pigment epithelial tissue adjacent to the bed; and (4) corresponding, sharply demarcated hypo- and hyperfluorescence on fluorescein angiography. More chronic lesions were recognised by characteristics established in the study of repair after acute tears. ${ }^{15}$ Excluded from the study were patients aged less than 55 years as well as those with inadequate photographic or clinical documentation.

Seventy-three individuals were diagnosed as having a pigment epithelial tear in at least one eye; 41 were females aged 56 to 84 years (mean 70.6 years), and 32 males aged 55 to 82 years (mean 71 years). Photographic, angiographic, and clinical data were evaluated on all 73 patients. Eleven were excluded because of opaque media in one eye, the application of laser photocoagulation to a pigment epithelial detachment, or inadequate documentation. The length of review ranged from one to 126 months. In 1986 all subjects were invited for further examination in order to provide as long a period of review as possible. 


\section{Results}

Forty-five of the 62 patients had bilateral visual loss either at presentation or lost vision in the second eye during the review period (Table 1).

Of the 40 patients who were seen initially with a pigment epithelial tear in one eye and contralateral good vision 23 lost vision in the second eye during the period of review, 14 from a tear of the pigment epithelium, four from primary neovascular disciform lesions, two from undetermined cause, one from

Table 1 Cause of visual loss in the contralateral eye in those patients with bilateral visual loss

\begin{tabular}{llllll}
\hline $\begin{array}{c}\text { Visual loss } \\
\text { at presentation }\end{array}$ & Total & Tear & NV & Other & Uncertain \\
\hline First eye & 23 & 14 & 4 & 3 & 2 \\
Second eye & 22 & 10 & 4 & 0 & 8 \\
\hline
\end{tabular}

NV: subretinal neovascular lesion.

geographic atrophy, and two from long-standing pigment epithelial detachment. The remainder retained useful vision in the contralateral eye. All had drusen, and some had atrophy or detachment of the pigment epithelium at the most recent review.

At presentation 22 patients had prior loss of central vision in the first eye at the time of diagnosis of a tear in the second. The nature of the lesion in the first eye was sought. A pigment epithelial tear could be diagnosed with assurance on the basis of clinical appearance and angiography in 10. Choroidal neovascularisation was evident as the primary event in four eyes. In the remaining eight, many of whom were seen three years or more after loss of vision, it was not possible to distinguish between a pigment epithelial tear and a primary neovascular disciform lesion in the eye with prior visual loss.

\section{Discussion}

This study implies that pigment epithelial tears occur frequently in both eyes; of the 45 patients with bilateral visual loss 24 had evidence of a tear in each eye. True bilaterality may be somewhat higher, since in eight patients one eye was examined late in the evolution of the lesion, at a time when a tear would no longer be identifiable. This can be compared with an estimated $1 \%$ risk of loss of vision in both eyes due to a tear if bilateral involvement were due to chance alone. In a hospital based population survey it was found that pigment epithelial detachments comprised approximately $10 \%$ of exudative macular lesions in age related macular disease, ${ }^{16}$ and in a natural history study $10 \%$ pigment epithelial detachments sustained a tear. ${ }^{9}$
The high prevalence of bilaterality of pigment epithelial rips suggests that these patients may have particular attributes of age related change at the level of Bruch's membrane which lead to this complication. That the specific changes required to produce this complication might affect both eyes similarly would be expected given the demonstrated symmetry of drusen as a clinical manifestation of age related macular disease. ${ }^{1718}$

The hypothesis that these patients have Bruch's membrane changes which differ from those which precipitate other complications of age related disease $^{19}$ now appears to be testable. This could be achieved by documenting the fundus changes in the fellow eyes of those with a retinal pigment epithelial tear, since this study shows that these eyes have a high risk of suffering a similar fate.

This study was supported in part by Medical Research Council grant number G.8320019 N.

\section{References}

1 Hoskin A, Bird AC, Sehmi K. Tears of detached retinal pigment epithelium. Br J Ophthalmol 1981; 65: 417-22.

2 Coscas G, Quentel G, Pinon F, Soubrane G. Déchirure spontanée de l'epithelium pigmentaire dans la région maculaire. Bull Soc Ophthalmol Fr 1982; 82: 815-20.

3 Cantrill HL, Ramsay RC, Knobloch WH. Rips in the pigment epithelium. Arch Ophthalmol 1983; 101: 1074-9.

4 Green SN, Yarian D. Acute tear of the retinal pigment epithelium. Retina 1983; 3: 16-20.

5 Decker WL, Sanborn GE, Ridley M, Annesley WH, Sorr EM. Retinal pigment epithelial tears. Ophthalmology 1983; 90: 507-12.

6 Gass JDM. Pathogenesis of tears of the retinal pigment epithelium. Br J Ophthalmol 1984; 68: 513-9.

7 Gass JDM. Retinal pigment epithelial rip during krypton red laser photocoagulation. Am J Ophthalmol 1984; 98: 700-6.

8 Swanson DE, Kalina RE, Guzak SV. Tears of the retinal pigment epithelium. Retina $1984 ; 4: 115-8$.

9 Casswell AG, Kohen D, Bird AC. Retinal pigment epithelial detachments in the elderly: classification and outcome. $\mathrm{Br} J$ Ophthalmol 1985; 69: 397-403.

10 Sunakawa M, Tsukahara I. Tear of the retinal pigment epithelium and serous retinal detachment. Am J Ophthalmol 1985; 100: 488-9.

11 Krishan NR, Chandra SR, Stevens TS. Diagnosis and pathogenesis of retinal pigment epithelial tears. Am J Ophthalmol 1985; 100: 698-707.

12 De Laey JJ, Riems D. Ripping of detached retinal pigment epithelium in senile macular degeneration. Bull Soc Belge Ophtalmol 1985; 207: 27-35.

13 Tutein-Nolthenius PA, Deutman AF. Rips of the retinal pigment epithelium. Int Ophthalmol 1985; 8: 19-23.

14 Traboulsi EI, Jalkh AE. Retinal pigment epithelium tear as a cause of vitreous hemorrhage. Ann Ophthalmol 1985; 17: 228-37.

15 Chuang EL, Bird AC. Repair after tears of the retinal pigment epithelium. Eye, in press.

16 Grey RHB, Bird AC, Chisholm IH. Senile disciform macular degeneration: features indicating suitability for photocoagulation. Br J Ophthalmol 1979; 63: 85-9.

17 Leibowitz HM, Krueger DE, Maunder LR, et al. Framingham 
Eye Study Monograph. Surv Ophthalmol 1980; 24(suppl): 428-71.

18 Coffrey AJH, Brownstein S. The prevalence of macular drusen in postmortem eyes. Am J Ophthalmol 1986; 102: 164-71.
19 Bird AC, Marshall J. Retinal pigment epithelial detachments in the elderly. Trans Ophthalmol Soc UK 1986; 105: 674-82.

Accepted for publication 30 December 1987. 